\title{
Generalized conditioned reinforcement in satiated rats'
}

JOHN A. NEVIN

SWARTHMORE COLLEGE

A buzzer was established as a discriminative stimulus for rats in six different training procedures with food or water reinforcement. When the rats were satiated and tested in a new situation, they acquired a preference for a response which produced the buzzer, and responded differentially in a stimulus correlated with availability of the buzzer.

Investigation of positive conditioned reinforcement with a new response, in a novel setting and in the absence of the training drive, is important in determining the limits of the generality of conditioned reinforcement (Keller \& Schoenfeld, 1950, Ch. 8). Skinner (1953, Ch. 5) has suggested that a stimulus paired with several different primary reinforcers might be especially effective as a generalized conditioned reinforcer in a variety of situations and deprivation conditions. This report describes the establishment of differential responding in satiated rats in a novel situation, using as reinforcement a stimulus which had functioned as a discriminative stimulus in several different training procedures with food or water reinforcement.

\section{Subjects}

Four male brown rats from the Swarthmore colony, about four months old, were deprived of food or water for $22 \mathrm{hr}$. before each session, depending on the scheduled reinforcer. Two control rats were maintained on matched deprivation schedules for the duration of the experiment.

\section{Apparatus}

Training was conducted in a 6-ft. runway, a $\mathrm{T}$-maze with 3-ft. arms, a Skinner box with pellet dispenser, and another Skinner box of different design with a water dipper. Both Skinner boxes had pigeon keys mounted next to the reinforcement magazine, and a chain could be suspended from a microswitch overhead. No attempt was made to shield the apparatus from sounds or changes in room light. The test for conditioned reinforcement was run in a chamber designed to be radically different from the training apparatus. Contact levers were mounted at opposite ends of a box with wooden sides, 10 in. $\times 4$ in., 4 in. above the hardware cloth floor. This chamber was inside a refrigerator maintained at room temperature; light could be provided by a 15 watt bulb above the chamber.

Training

(1) Twenty-five trials in the runway, with a buzzer sounding when the rat advanced $18 \mathrm{in}$. from the start box, and remaining on until the rat made contact with the reinforcer. This was followed by 40 trials of discrimi- nation training, in which trials with buzz and reinforcement alternated randomly with trials without buzz or reinforcement. Rats 1 and 2 ran for food, Rats 3 and 4 ran for water.

(2) Operant discrimination training (cued DRL) for 10 30-min. sessions in the Skinner boxes. Reinforcement was available only for responses spaced at least $18 \mathrm{sec}$. apart. A buzzer sounded when $18 \mathrm{sec}$. had elapsed without a response, and terminated with the reinforced response. Rats 1 and 2 pulled a chain for food, Rats 3 and 4 pressed a nose key for water.

(3) Forty trials with reinforcement available on the left in the $\mathrm{T}$-maze, followed by 20 trials with reinforcement on the right, correction method. A buzzer sounded when the rat advanced 18 in. into the correctarm of the maze, and stayed on until the rat made contact with the reinforcer. Rats 1 and 2 ran for water, Rats 3 and 4 for food.

(4) Ten more 30-min. sessions of cued DRL. Rats 1 and 2 pressed a nose key for water, Rats 3 and 4 pulled a chain for food.

(5) Fourteen 30-min. sessions on cued DRL with a limited hold: if the response did not occur within $3 \mathrm{sec}$. of buzz onset, the buzzer went off again for $18 \mathrm{sec}$. Rats 1 and 2 pulled a chain for water, Rats 3 and 4 pressed a nose key for food.

(6) Fifteen 30-min. sessions on cued DRL with $3 \mathrm{sec}$. limited hold, and with reinforcement available randomly in only $25 \%$ of the buzz periods. Rats 1 and 2 pressed a nose key for food, Rats 3 and 4 pulled a chain for water.

Testing

One or two days after this training, each rat was given $2 \mathrm{hr}$. access to both food and water. It was then placed in the two-bar test chamber inside the dark refrigerator for a 30-min. operant level determination, during which responses were without effect. This was followed immediately by a 90-min. period in which every response on the non-preferred bar (bar A) produced a 1-sec. buzz. The two control rats, which had no experimental histories of any sort, were similarly satiated and tested to determine whether the buzzer possessed reinforcing properties in its own right.

On the next two days, the experimental rats were again given $2 \mathrm{hr}$. access to food and water, and tested for 60 min. in the same apparatus. Periods of light and dark alternated every $90 \mathrm{sec}$. When the light was on, touching bar A (the bar which produced the buzzer in original testing) produced a 1-sec. buzz; when the light was off, the buzz was not available. 


\section{Results}

No results for training will be presented, beyond noting that there was clear evidence of discriminative control by the buzzer for all rats in all procedures.

In the first test session, all rats started responding on both bars at fairly high rates, which declined to low levels by the end of the 30-min. operant level period. When the buzzer was first presented for touching bar $\mathrm{A}$, all four rats increased their rates on bar A for $10 \mathrm{~min}$., relative to the last $10 \mathrm{~min}$. of operant level. There were smaller increases on the other bar for three rats, and a decrease for the fourth. The increases were transient and highly variable across Ss. However, a change in preference for bar A was evident for the remainder of the session. The mean number of responses on both bars, and the proportion of responses on bar A over the course of the session, are shown in Fig. 1. These functions are representative of the behavior of all four experimental rats. The increase in the proportion of responses on bar A when it could produce the buzzer was significant at the .01 level for Rats 1,2 , and 3 , and at the .05 level for Rat 4 , by a chi square test against expectancies based on operant level preferences.

One control rat exhibited a transient increase in rate on bar A when the buzzer was first made available, but the increase on the other bar was larger. Rate decreased on both bars for the second rat. Both rats gave evidence of decreases in the proportion of responses on bar $\mathrm{A}$ when it could produce the buzzer. Accordingly, the preference shift exhibited by the experimental rats cannot be due to the effects of the buzzer per se, and must be attributed to conditioned reinforcement.

In the second test session, a decrease in overall rate with time was again evident. However, the proportion of all responses made in light, when the buzzer was available, increased as the session progressed. The mean data for bar $\mathrm{A}$ are given in Fig. 2; no data for the other bar were recorded. All four rats made more

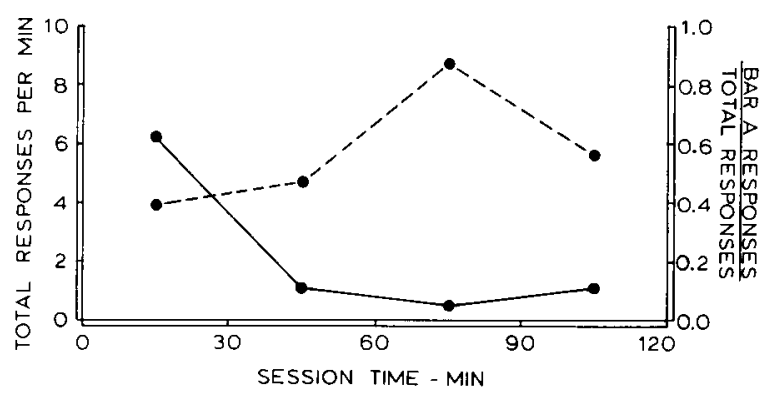

Fig. 1. Mean rate of responding on both bars (solid line, left hand ordinate) and the mean proportion of responses on bar $A$ (dashed line, right hand ordinate) over the course of the first test session for the four experimental rats. For the first $30 \mathrm{~min}$., responses had no effect; for the remainder of the session, responses on bar $A$ were followed by a 1 sec. buzz.

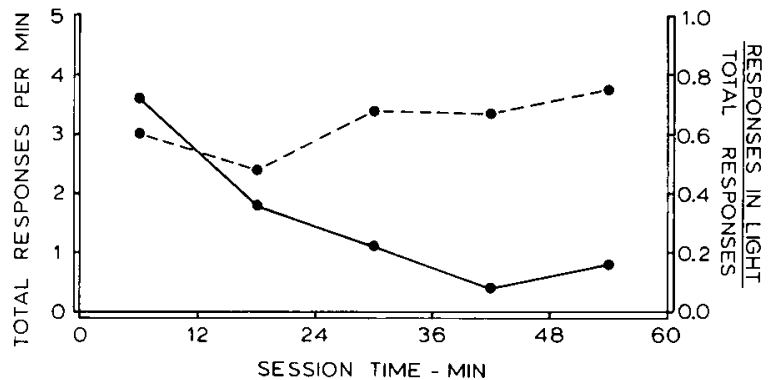

Fig. 2. Mean rate of responding (solid line, left hand ordinate) and the mean proportion of responses in the presence of a light (dashed line, right hand ordinate) over the course of the second test session for the four experimental rats. Light and dark alternated every $90 \mathrm{sec}$; responses in the presence of the light were fnllowed by a 1 sec. buzz.

responses in the light than in darkness during the last $36 \mathrm{~min}$. of the session. Chi square tests indicated that this difference was significant beyond the .01 level for Rats 2 and 4; the difference was not significant for Rats 1 and 3. Thus, there is evidence that differential responding on a single bar, as well as a preference shift, could be established by conditioned reinforcement.

In the third test session, overall levels of responding were lower, and the buzzer had no consistent effect.

\section{Discussion}

A reinforcing stimulus is usually identified by an increase in the rate of a response upon which the stimulus is contingent. In this study, there was only a small, transient increase in responding on bar A when buzzer was available. However, the buzzer established and maintained a preference for bar A. This relative strengthening of the reinforced response class, despite a decrease in total responding, is similar to the effects in human Ss of verbal reinforcement for saying plural nouns (Greenspoon, 1955).

In the second test, acquisition of differential responding in a stimulus correlated with availability of the buzzer was demonstrated, again with a decrease in total responding. It is suggested that weak conditioned reinforcing effects may best be measured by changes in relative rather than absolute rate of responding.

\section{References}

Greenspoon, J. The reinforcing effects of two spoken sounds on the frequency of two responses. Amer. J. Psychol., 1955, 68, 409-416.

Keller, F. S., \& Schoenfeld, W. N. Principles of psychology. New York: Appleton-Century-Crofts, 1950.

Skinner, B. F. Science and human behavior. New York: MacMillan, 1953.

\section{Note}

1. This research was supported by Grant 08515-02 from the National Institute of Mental Health to Swarthmore College. I thank Gerald Zimmerman for his valuable assistance. 